OPEN ACCESS

Edited by:

Hongbo $L i$

Beijing Institute of Technology, China

Reviewed by:

Jialong Zhao,

Jilin Normal University, China

Aiwei Tang

Beijing Jiaotong University, China

*Correspondence:

Qingli Lin

qingli1112@126.com

Hongzhe Wang

whz@henu.edu.cn

Specialty section:

This article was submitted to

Nanoscience,

a section of the journal

Frontiers in Chemistry

Received: 04 February 2020

Accepted: 18 March 2020

Published: 23 April 2020

Citation:

$X u Q, L i X$, Lin Q, Shen H, Wang H and Du Z (2020) Improved Efficiency of All-Inorganic Quantum-Dot Light-Emitting Diodes via Interface Engineering. Front. Chem. 8:265. doi: 10.3389/fchem.2020.00265

\section{Improved Efficiency of All-Inorganic Quantum-Dot Light-Emitting Diodes via Interface Engineering}

\author{
Qiulei Xu, Xinyu Li, Qingli Lin*, Huaibin Shen, Hongzhe Wang* and Zuliang Du \\ Key Lab for Special Functional Materials, Ministry of Education, National and Local Joint Engineering Research Center for \\ High-Efficiency Display and Lighting Technology, Collaborative Innovation Center of Nano Functional Materials and \\ Applications, School of Materials Science and Engineering, Henan University, Kaifeng, China
}

As the charge transport layer of quantum dot (QD) light-emitting diodes (QLEDs), metal oxides are expected to be more stable compared with organic materials. However, the efficiency of metal oxide-based all-inorganic QLEDs is still far behind that of organic-inorganic hybrid ones. The main reason is the strong interaction between metal oxide and QDs leading to the emission quenching of QDs. Here, we demonstrated nickel oxide $\left(\mathrm{NiO}_{\mathrm{x}}\right.$ )-based all-inorganic QLEDs with a maximum current efficiency of $20.4 \mathrm{~cd} \mathrm{~A}^{-1}$ and external quantum efficiency (EQE) of $5.5 \%$, which is among the most efficient all-inorganic QLEDs. The high efficiency is mainly attributed to the aluminum oxide $\left(\mathrm{Al}_{2} \mathrm{O}_{3}\right)$ deposited at the $\mathrm{NiO}_{x} /$ QDs interface to suppress the strong quenching effect of $\mathrm{NiO}_{x}$ on the QD emission, together with the molybdenum oxide $\left(\mathrm{MoO}_{x}\right)$ that reduced the leakage current and facilitated hole injection, more than 300\% enhancement was achieved compared with the pristine $\mathrm{NiO}_{x}$-based QLEDs. Our study confirmed the effect of decorating the $\mathrm{NiO}_{x} / \mathrm{QDs}$ interface on the performance enhancement of the all-inorganic QLEDs.

Keywords: $\mathrm{NiO}_{x}$, all-inorganic, quantum dots, light-emitting devices, high efficiency

\section{INTRODUCTION}

Quantum dots (QDs) have many advantages including high color purity, high photoluminescence (PL) quantum yield (QY), and high stability, which make them promising luminescent materials for light-emitting diodes (LEDs) (Anikeeva et al., 2009; Bae et al., 2013; Shirasaki et al., 2013; Shen et al., 2015; Chen et al., 2018; Cao et al., 2019; Zhang et al., 2019). Recently, the performance of QD LEDs (QLEDs) has been improved greatly, the external quantum efficiencies (EQEs) for tricolor QLEDs have all surpassed 20\%, with peak EQEs of 30.4\% for red, $22.9 \%$ for green, and $19.8 \%$ for blue QLEDs, respectively (Wang et al., 2017; Shen et al., 2019; Song et al., 2019). At present, highly efficient QLEDs are mainly based on hybrid organic-inorganic structure, in which poly(3,4ethylenedioxythiophene) polystyrene sulfonate (PEDOT:PSS) is widely used as the hole injection layer (HIL); poly[N,N'-bis(4-butylphenyl)-N,N'-bis(phenyl)benzidine] (Poly-TPD), poly\{9,9dioctylfluorene-co-N-[4-(3-methylpropyl)]diphenylamine\} (TFB), or poly(N-vinyl carbazole) $(\mathrm{PVK})$ are adopted as the hole transport layer $(\mathrm{HTL})$; and zinc oxide $(\mathrm{ZnO})$ nanoparticles (NPs) are used as the electron transport layer (ETL) (Qian et al., 2011; Dai et al., 2014; Zhang et al., 2019). As we know, organic materials are sensitive to moisture and may degrade under high operating currents, which affect the stability of devices, and consequently, the strict encapsulation technology is indispensable. To solve this problem, it is necessary to seek more stable hole transport materials that can endure a high carrier density at high luminance. 
Many inorganic metal oxides [nickel oxide $\left(\mathrm{NiO}_{\mathrm{x}}\right)$, tungsten oxide $\left(\mathrm{WO}_{\mathrm{x}}\right)$, molybdenum oxide $\left(\mathrm{MoO}_{\mathrm{x}}\right)$, vanadium oxide $\left(\mathrm{VO}_{\mathrm{x}}\right)$, etc.] have been applied as HIL in optical electronic devices to improve the device stability (Murase and Yang, 2012; Huu Tuan et al., 2014; Yang et al., 2014; Zhang et al., 2017), and $\mathrm{NiO}_{\mathrm{x}}$ is a promising hole transport material among them due to its nature of intrinsic p-type semiconductor with a wide bandgap and high transparency. Moreover, $\mathrm{NiO}_{\mathrm{x}}$ possesses relatively proper band energy for efficient hole injection and electron blocking to confine the excitons in the QD emitting layer $[\sim 5.2 \mathrm{eV}$ for the valance band maximum (VBM) and $\sim 1.6 \mathrm{eV}$ for the conductive band minimum (CBM)]. Nevertheless, $\mathrm{NiO}_{\mathrm{x}}$-based all-inorganic QLEDs with ZnO as ETL exhibited poor efficiency (Mashford et al., 2010), which is mainly attributed to two reasons. First, the higher electron mobility $\left[\sim 10^{-2} \mathrm{~cm}^{2}(\mathrm{~V} \cdot \mathrm{s})^{-1}\right]$ of $\mathrm{ZnO}$ NPs and small energy barrier of the conductive band at the QDs/ZnO interface lead to imbalanced carrier transport due to easier electron injection. Second, the excitons formed near the $\mathrm{NiO}_{\mathrm{x}}$ layer are subject to the surface of $\mathrm{NiO}_{\mathrm{x}}$, and a large number of free carriers and defects/traps on the surface of adjacent $\mathrm{NiO}_{\mathrm{x}} \mathrm{HTL}$ leads to the quenching of QD emission (Caruge et al., 2006, 2008; $\mathrm{Wu}$ and Yeow, 2010). It is reported that many dipolar surface species of $\mathrm{NiOOH}$ are present on the solution-processed $\mathrm{NiO}_{\mathbf{x}}$ films and induce a strong localized electric field, which facilitates radiationless decay channels with a charge-transfer/charging and/or energy transfer processes and leads to a severe decrease of device efficiency (Ratcliff et al., 2011; Liu et al., 2015).

To address this issue, a modification of the $\mathrm{NiO}_{\mathrm{x}} / \mathrm{QD}$ interface is needed. Several kinds of buffer layer have been inserted to suppress the exciton quenching induced by $\mathrm{NiO}_{\mathrm{x}}$. By introducing ultrathin aluminum oxide $\left(\mathrm{Al}_{2} \mathrm{O}_{3}\right)$ layer at the $\mathrm{NiO}_{\mathrm{x}} / \mathrm{QD}$ layer interface (Zhang et al., 2016; Ji et al., 2017, 2018), Ji et al. fabricated highly efficient green all-inorganic QLEDs, in which over $800 \%$ enhancement for the current efficiency/EQE of up to $34.1 \mathrm{~cd} \cdot \mathrm{A}^{-1 / 8.1 \%}$ was achieved when the $\mathrm{Al}_{2} \mathrm{O}_{3}$ layer was obtained by atomic layer deposition (ALD), and this represented the highest EQE for all-inorganic QLEDs reported ever. With ultrathin lithium fluoride (LiF) being inserted at the $\mathrm{NiO}_{\mathrm{x}} / \mathrm{QD}$ interface and ultrathin $\mathrm{Al}_{2} \mathrm{O}_{3}$ being inserted between the QDs and $\mathrm{ZnO}$ layer (Yang et al., 2018), Yang et al. reported highly efficient all-inorganic QLEDs with a maximum EQE of $6.52 \%$ and a long device life time of $16,120 \mathrm{~h}$ at $100 \mathrm{~cd} \cdot \mathrm{m}^{-2}$. Li et al. reported all-inorganic QLEDs of the highest maximum brightness of $40,000 \mathrm{~cd} \cdot \mathrm{m}^{-2}$ by sputtering ultrathin $\mathrm{MgO}$ at the $\mathrm{NiMgO} / \mathrm{QD}$ interface; however, the maximum EQE is only $1.5 \%$ (Jiang et al., 2019). These results indicate the importance of decoration of the $\mathrm{NiO}_{\mathrm{X}} / \mathrm{QD}$ interface on suppressing the QD emission quenching and improving the performance of the all-inorganic QLED efficiency. Among them, the $\mathrm{Al}_{2} \mathrm{O}_{3}$ buffer layer obtained by ALD technology has more advantages since the film thickness can be precisely controlled at atomic level by alternating the exposure cycle of trimethylaluminum $\left[\mathrm{Al}\left(\mathrm{CH}_{3}\right)_{3}\right]$ and $\mathrm{H}_{2} \mathrm{O}$, and the asprepared films possess good uniformity over large substrates and excellent conformality on three-dimensional surface topologies. Furthermore, the hydroxyl $(-\mathrm{OH})$ in the $\mathrm{NiOOH}$ species can be consumed during the exposure to $\mathrm{Al}\left(\mathrm{CH}_{3}\right)_{3}$ deposition cycles. Nevertheless, the maximum EQE for all-inorganic QLEDs with $\mathrm{Al}_{2} \mathrm{O}_{3}$ buffer layer is still very low, which is likely due to imbalanced carrier transport in devices resulting from the inefficient hole injection from indium tin oxide (ITO) to the $\mathrm{NiO}_{\mathrm{x}}$ layer and the relatively higher energy barrier between the $\mathrm{NiO}_{\mathrm{x}}$ layer and QD layer. To solve this problem, more researches are still needed to optimize the structure of $\mathrm{NiO}_{\mathrm{x}}$-based allinorganic QLEDs and improve the device efficiency.

Here, we demonstrated highly efficient all-inorganic QLEDs with an optimized structure of ITO/solution-processed $\mathrm{MoO}_{\mathrm{x}}$ $\left(\mathrm{sMoO}_{\mathrm{x}}\right) / \mathrm{NiO}_{\mathrm{x}} / \mathrm{Al}_{2} \mathrm{O}_{3} / \mathrm{QDs} / \mathrm{ZnO} / \mathrm{Al}$ through all solutionprocess method except for $\mathrm{Al}_{2} \mathrm{O}_{3}$ layer and the electrodes. The ultrathin $\mathrm{Al}_{2} \mathrm{O}_{3}$ inserted at the $\mathrm{NiO}_{\mathrm{x}} / \mathrm{QDs}$ interface was to suppress the strong quenching effect of $\mathrm{NiO}_{\mathrm{x}}$ on the emission of QD. And the $\mathrm{sMoO}_{\mathrm{x}}$ introduced before the $\mathrm{NiO}_{\mathrm{x}}$ layer was aimed to reduce leakage current and facilitate the hole injection from anode to the emitting layer and minimize the hole-blocking effect of $\mathrm{Al}_{2} \mathrm{O}_{3}$ layer. Our resultant all-inorganic QLEDs reached a high current efficiency of $20.4 \mathrm{~cd} \mathrm{~A}^{-1}$ and a maximum EQE of $5.5 \%$, more than $300 \%$ enhancement was achieved compared with the pristine $\mathrm{NiO}_{\mathrm{x}}$-based QLEDs.

\section{MATERIALS AND METHODS \\ Preparation of Green Quantum Dots and Metal Oxide Solution}

Cadmium selenide (CdSe)/zinc sulfide ( $\mathrm{ZnS}$ ) QDs were synthesized according to the method reported in the literature (Li et al., 2019). The QDs in octane solution exhibited a green emission with the PL peak at $525 \mathrm{~nm}$ (Supplementary Figure 1). The $\mathrm{NiO}_{\mathrm{x}}$ precursor was prepared by a modified method (Mashford et al., 2010); the mixture of nickel acetate tetrahydrate $\left[\mathrm{Ni}(\mathrm{OAc})_{2} \cdot 4 \mathrm{H}_{2} \mathrm{O}\right.$; purchased from Aldrich] and equimolar quantity of monoethanolamine (MEA; purchased from Aldrich) in ethanol was heated at $60^{\circ} \mathrm{C}$ for $2 \mathrm{~h}$ and stirred overnight. $0.1 \mathrm{M} \mathrm{MoO}_{\mathrm{x}}$ solutions were synthesized by a thermal decomposition method using ammonium heptamolybdate $\left[\left(\mathrm{NH}_{4}\right)_{6} \mathrm{Mo}_{7} \mathrm{O}_{24} \cdot 4 \mathrm{H}_{2} \mathrm{O}\right]$ as a precursor (Murase and Yang, 2012; $\mathrm{Vu}$ et al., 2016). The ZnO NPs were prepared by slowly mixing $0.1 \mathrm{M}$ zinc acetate in dimethyl sulfoxide (DMSO) and $0.3 \mathrm{M}$ tetramethylammonium hydroxide (TMAH) in ethanol together for $1 \mathrm{~h}$, and the $\mathrm{ZnO}$ particles were precipitated by adding hexane/ethanol to the solution.

\section{Fabrication of Quantum Dot Light-Emitting Diode Devices}

The all-inorganic QLED structure consists of ITO/ $\mathrm{MoO}_{\mathrm{x}} / \mathrm{NiO}_{\mathrm{x}} / \mathrm{Al}_{2} \mathrm{O}_{3}$ ( $x$ cycles)/QDs/ZnO/Al. The $\mathrm{NiO}_{\mathrm{x}}$, QDs, and $\mathrm{ZnO}$ are used as HTL, emission layer, and ETL, respectively. Before fabricating the devices, the ITO substrates were ultrasonically cleaned in detergent, DI water, acetone, and isopropyl alcohol for $15 \mathrm{~min}$ successively followed by an ex situ UV ozone treatment in air for $15 \mathrm{~min}$. This as-prepared $\mathrm{MoO}_{\mathrm{x}}$ precursor solution was spin-coated onto the UV ozone-treated ITO substrates at $4,000 \mathrm{rpm}$ and then baked at $120^{\circ} \mathrm{C}$ for $10 \mathrm{~min}$ to get the $\mathrm{MoO}_{\mathrm{x}}$ film. Then, the $\mathrm{NiO}_{\mathrm{x}}$ precursor was spin-coated at $2,000 \mathrm{rpm}$ and annealed at $275^{\circ} \mathrm{C}$ for $30 \mathrm{~min}$ in air to obtain 
a highly conductive layer. The $\mathrm{Al}_{2} \mathrm{O}_{3}$ layer was deposited by alternating exposures of $\mathrm{Al}\left(\mathrm{CH}_{3}\right)_{3}$ and $\mathrm{H}_{2} \mathrm{O}$ with the same substrate and maintaining the temperature at $200^{\circ} \mathrm{C}$, and the thickness is approximately $0.1 \mathrm{~nm}$ for each ALD cycle. $\mathrm{Al}_{2} \mathrm{O}_{3}$ layers with different thicknesses were deposited on the $\mathrm{NiO}_{\mathrm{x}}$ films for device A (zero cycle), B (one cycle), C (two cycles), and $\mathrm{D}$ (three cycles), respectively. Note that no $\mathrm{MoO}_{\mathrm{x}}$ layers were inserted for devices $\mathrm{A}$ to $\mathrm{C}$, and device $\mathrm{A}$ is a control device without the $\mathrm{Al}_{2} \mathrm{O}_{3}$ interlayer. The QD octane solution (18 $\mathrm{mg} \cdot \mathrm{ml}^{-1}$ ) was then spin-coated on the $\mathrm{NiO}_{\mathrm{x}} / \mathrm{Al}_{2} \mathrm{O}_{3}$ layer at 2,000 rpm in $\mathrm{N}_{2}$-filled glove box. After that, $\mathrm{ZnO}$ ethanol solution $\left(30 \mathrm{mg} \cdot \mathrm{ml}^{-1}\right.$ ) was spin-coated at 2,000 rpm and annealed at $60^{\circ} \mathrm{C}$ for $30 \mathrm{~min}$ to remove the residual solvent. Finally, the $\mathrm{Al}$ cathode was thermal evaporated in the vacuum chamber at pressure below $4 \times 10^{-6}$ Torr. The $\mathrm{Al}$ cathode lines with a width of $2.0 \mathrm{~mm}$ were deposited orthogonally to the $2 \mathrm{~mm}$ ITO anode lines to form a $4 \mathrm{~mm}^{2}$ active area.

\section{Measurements and Characterization}

Current density-voltage-luminance (J-V-L) characteristics of QLEDs were tested using a Keithley 2400 source meter and a picoammeter (Keithley 6485) with a calibrated Newport silicon diode under ambient conditions. The luminance was calibrated using a Minolta luminance meter (CS-100). The electroluminescence spectra were obtained with an Ocean Optics spectrometer (USB2000, relative irradiance mode) and a Keithley 2400 source meter. The room temperature PL spectrum of the QDs in octane was collected by the Ocean Optics Maya 2000Pro spectrometer under an excitation wavelength of $365 \mathrm{~nm}$. Time-resolved PL (TRPL) measurements were carried out with Edinburgh Instruments FL920 spectrometer, utilizing a 400-nm excitation light source. X-ray photoelectron spectroscopy (XPS) was obtained using a Kratos Axis-Ultra spectrometer with a monochromatic $\mathrm{Al} \mathrm{K} \alpha$ source, $15 \mathrm{kV} / 8 \mathrm{~mA}$. The atomic force microscopy (AFM) images were recorded in the tapping mode by Bruker Multimode-8. The UV photoelectron spectroscopy (UPS; Thermo Scientific ESCALAB $250 \mathrm{XI}$ ) measurement was performed using a He I discharge lamp $(\mathrm{hv}=21.22 \mathrm{eV})$ under high vacuum $\left(2.5 \times 10^{-8}\right.$ mbar $)$ and the UPS spectra of $\mathrm{MoO}_{\mathrm{x}}$ and $\mathrm{NiO}_{\mathrm{x}}$ was meaured (Supplementary Figure 4).

\section{RESULTS AND DISCUSSION}

The composition of the solution-processed $\mathrm{NiO}_{\mathrm{x}}$ films was studied by XPS analysis. Figure 1A shows the XPS spectrum for $\mathrm{Ni} 2 \mathrm{p}_{3 / 2}$ state possessing three peaks. The first peak centered at a binding energy of $854.2 \mathrm{eV}$ corresponds to $\mathrm{Ni}^{2+}$ in the standard $\mathrm{Ni}-\mathrm{O}$ octahedral bonding configuration in cubic rock salt $\mathrm{NiO}_{\mathrm{x}}$. The adjacent peak shoulder located at $855.9 \mathrm{eV}$ was ascribed to $\mathrm{Ni}^{2+}$ vacancy-induced $\mathrm{Ni}^{3+}$ ion and $\mathrm{NiOOH}$ (Sasi and Gopchandran, 2007; Manders et al., 2013). The broad peak centered at $861.0 \mathrm{eV}$ has been ascribed to a shake-up process in the NiO structure. Figure 1B shows the XPS spectrum for the $\mathrm{O} 1 \mathrm{~s}$ state, the peak centered at $529.5 \mathrm{eV}$ confirms the Ni-O octahedral bonding in $\mathrm{NiO}_{\mathrm{x}}$. The peak at $531.2 \mathrm{eV}$ is indicative of nickel hydroxides and oxyhydroxides, including defective $\mathrm{NiO}_{\mathbf{x}}$ with hydroxyl groups adsorbed on the surface (Han et al., 2006; Ratcliff et al., 2011).

The morphology evolution of each layer within the QLEDs was assessed by atomic force microscopy (AFM; Figure 2). The root-mean-square (RMS) roughness of pure ITO (Supplementary Figure 2) is $2.38 \mathrm{~nm}$, and the value decreased to $1.23 \mathrm{~nm}$ after the spin-coating of $\mathrm{NiO}_{\mathrm{x}}$, which suggested that the ITO substrate was smoothed. The following ultrathin $\mathrm{Al}_{2} \mathrm{O}_{3}$ deposition (second cycle) had little effect on the roughness of the $\mathrm{NiO}_{\mathrm{x}}$ film. Then, the RMS roughness for substrate increased slightly as the layer number increased, which showed $1.51 \mathrm{~nm}$ for QD layer and $2.12 \mathrm{~nm}$ for $\mathrm{ZnO}$ layer, respectively.

Since $\mathrm{Al}_{2} \mathrm{O}_{3}$ is an insulating material, it is very important to control its thickness precisely via the ALD process. To get the optical thickness of $\mathrm{Al}_{2} \mathrm{O}_{3}$, we first fabricated allinorganic QLEDs consisting of a structure of ITO/NiO $/ \mathrm{Al}_{2} \mathrm{O}_{3}$ (n cycle)/QDs/ZnO/Al. Different deposition cycles of $\mathrm{Al}_{2} \mathrm{O}_{3}$ $(0 \mathrm{C}, 1 \mathrm{C}, 2 \mathrm{C}, 3 \mathrm{C})$ were applied at the $\mathrm{NiO}_{\mathrm{x}} / \mathrm{QD}$ interface, and the corresponding photoelectrical properties of devices were characterized and shown in Figure 3. $\mathrm{Al}_{2} \mathrm{O}_{3}$ showed
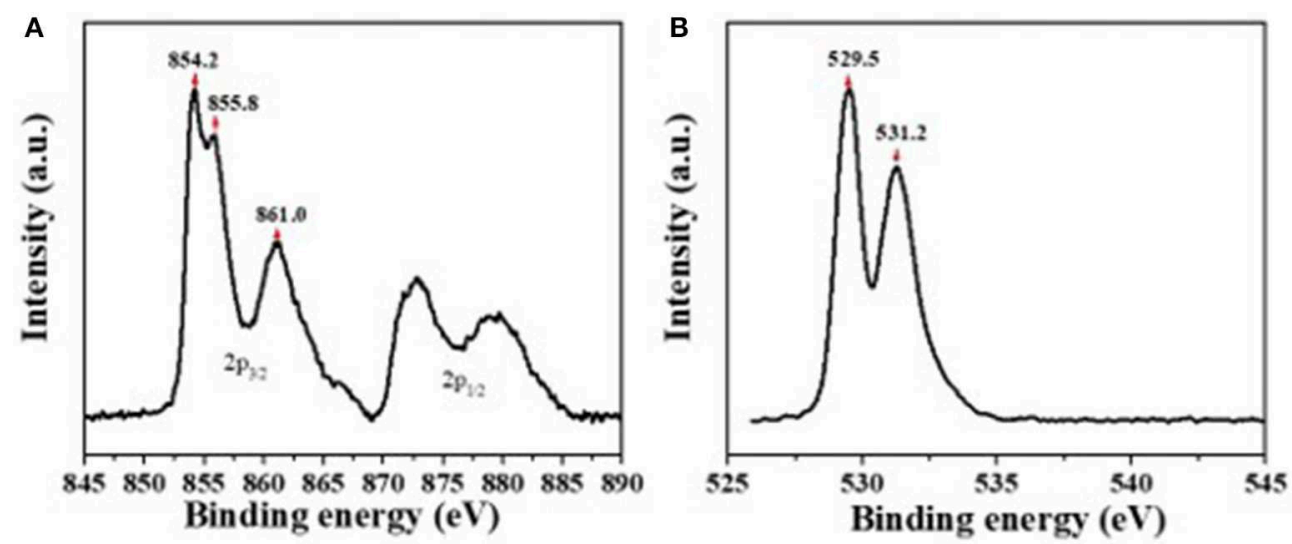

FIGURE 1 | The X-ray photoelectron spectroscopy (XPS) spectra for Ni 2p (A) and O1s (B) 


\section{A}

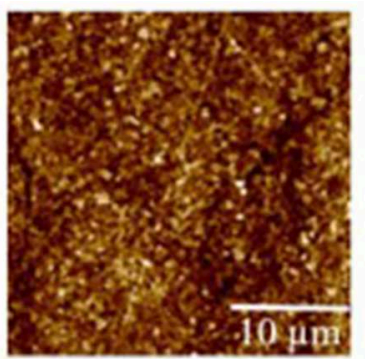

B

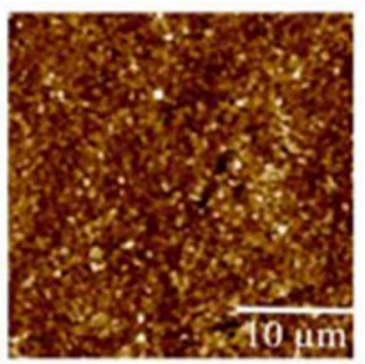

C

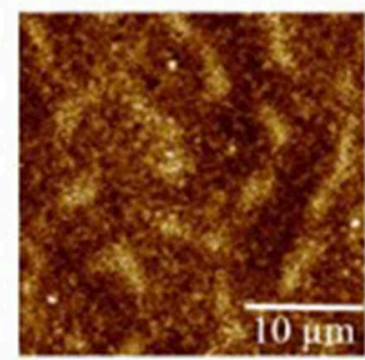

D

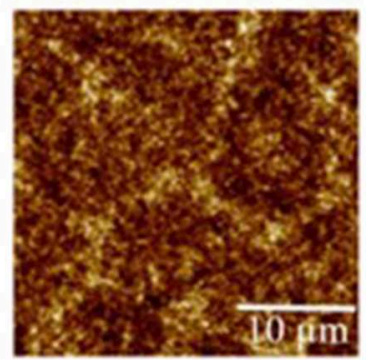

FIGURE 2 | Atomic force microscopy (AFM) images of (A) indium tin oxide (ITO)/nickel oxide $\left(\mathrm{NiO}_{x}\right)$, (B) ITO/NiO /aluminum oxide $\left(\mathrm{Al}_{2} \mathrm{O}_{3}\right)$ (two cycles), (C) ITO/NiO $/ \mathrm{Al}_{2} \mathrm{O}_{3}$ (two cycles)/quantum dots (QDs), and (D) ITO/ $\mathrm{NiO}_{x} / \mathrm{Al}_{2} \mathrm{O}_{3}$ (two cycles)/QDs/zinc oxide ( $\mathrm{ZnO})$. The corresponding root-mean-square (RMS) values of the samples are $1.23,1.24,1.51,2.12 \mathrm{~nm}$, respectively.

a remarkable influence on the performance of all-inorganic QLEDs. The current density decreased evidently with the increasing thickness of $\mathrm{Al}_{2} \mathrm{O}_{3}$ at a given voltage. For example, the current density for devices with even one cycle $(0.1 \mathrm{~nm})$ of $\mathrm{Al}_{2} \mathrm{O}_{3}$ deposition dropped to $1.4 \mathrm{~mA} \cdot \mathrm{cm}^{-2}$ at $5 \mathrm{~V}$, which is four times lower than that of the QLEDs without the $\mathrm{Al}_{2} \mathrm{O}_{3}$ layer. The reduced current density is probably due to the insulated $\mathrm{Al}_{2} \mathrm{O}_{3}$ layer, which limits the hole injection from $\mathrm{NiO}_{\mathrm{X}}$, and this can be confirmed by the lower hole density in hole-only devices consisting of ITO/ $/ \mathrm{NiO}_{\mathrm{x}} / \mathrm{Al}_{2} \mathrm{O}_{3} / \mathrm{QDs} / \mathrm{MoO}_{3} / \mathrm{Al}$ than that without the ultrathin $\mathrm{Al}_{2} \mathrm{O}_{3}$ layer (Supplementary Figure 3). The turnon voltage slightly increased from $4.1 \mathrm{~V}(0 \mathrm{C})$ to $4.4 \mathrm{~V}$ (3C) with the increasing thickness of $\mathrm{Al}_{2} \mathrm{O}_{3}$ layer. Despite the lower current density and higher turn-on voltage, the QLEDs with $\mathrm{Al}_{2} \mathrm{O}_{3}$ passivated layer exhibited more than $600 \%$ enhancement in luminance and more than $200 \%$ improvement in current efficiency and EQE (see Supplementary Table 1 in supporting information), which suggested that the emission quenching induced by $\mathrm{NiO}_{\mathrm{x}}$ played a more critical role in deterring the performance of $\mathrm{NiO}_{\mathrm{x}}$-based all-inorganic QLEDs. Particularly, devices with two cycles of $\mathrm{Al}_{2} \mathrm{O}_{3}$ deposition showed the highest current efficiency/maximum EQE of $12.8 \mathrm{~cd} \mathrm{~A}^{-1} / 3.5 \%$ at $5.5 \mathrm{~V}$, respectively.

To study the effect of ultrathin $\mathrm{Al}_{2} \mathrm{O}_{3}$ layer on the improvement of QLEDs performance, five samples were prepared, namely, F1: Glass/QDs, F2: $\mathrm{ITO} / \mathrm{NiO}_{\mathrm{x}} / \mathrm{QDs}$, F3: ITO/ $\mathrm{NiO}_{\mathrm{x}} / \mathrm{Al}_{2} \mathrm{O}_{3} \quad$ (1C)/QDs, F4: $\quad$ ITO $/ \mathrm{NiO}_{\mathrm{x}} / \mathrm{Al}_{2} \mathrm{O}_{3}$ (2C)/QDs/ZnO, and F5: ITO/ $\mathrm{NiO}_{\mathrm{x}} / \mathrm{Al}_{2} \mathrm{O}_{3}$ (3C)/QDs/ZnO, to measure their steady-state and time-resolved PL spectroscopy (as shown in Figure 4). The exciton lifetimes for different film
TABLE 1 | Summary of the PL peak and the decay lifetime for different samples.

\begin{tabular}{|c|c|c|}
\hline Sample & PL Peak (nm) & Lifetime (ns) \\
\hline QD in octane & 525 & \\
\hline F1: Glass/QDs & 528 & 7.3 \\
\hline F2: ITO/NiO $/$ /QDs & 532 & 5.2 \\
\hline F3: ITO/NiO $/ \mathrm{Al}_{2} \mathrm{O}_{3}(1 \mathrm{C}) / \mathrm{QDs}$ & 528 & 5.8 \\
\hline F4: ITO/NiO $/ \mathrm{Al}_{2} \mathrm{O}_{3}(2 \mathrm{C}) / \mathrm{QDs}$ & 528 & 6.0 \\
\hline F5: ITO/ $\mathrm{NiO}_{x} / \mathrm{Al}_{2} \mathrm{O}_{3}(3 \mathrm{C}) / \mathrm{QDs}$ & 528 & 6.0 \\
\hline
\end{tabular}

$\mathrm{Al}_{2} \mathrm{O}_{3}$, aluminum oxide; ITO, indium tin oxide; $\mathrm{NiO}_{x}$, nickel oxide; $P L$, photoluminescence; $Q D$, quantum dot.

samples were summarized in Table 1. It can be seen that the emission of QD film on glass substrate was peaked at $528 \mathrm{~nm}$ with an exciton lifetime of $7.3 \mathrm{~ns}$, while that on $\mathrm{NiO}_{\mathrm{x}}$ substrate red-shifted to $532 \mathrm{~nm}$ and the corresponding emission intensity and exciton lifetime decreased remarkably due to the interaction between QDs and $\mathrm{NiO}_{\mathrm{x}}$. For samples from F3 to F5, the PL peak blue-shifted to the original location of QD film $(528 \mathrm{~nm})$ with $\mathrm{Al}_{2} \mathrm{O}_{3}$ insertion, and the emission intensity and lifetime also showed an obvious increase, which confirmed the positive effect on passivating the surface of the $\mathrm{NiO}_{\mathrm{x}}$ layer and suppressing the emission quenching induced by $\mathrm{NiO}_{\mathrm{x}}$ through the introduction of the $\mathrm{Al}_{2} \mathrm{O}_{3}$ layer, and such results were consistent with the previously reported findings.

It is reported that the $\mathrm{sMoO}_{\mathrm{x}}$ film showed a higher work function of $5.6 \mathrm{eV}$, better transparency, and smoother surface morphology, providing the QLEDs with good Ohmic contact and small charge transfer resistance (He et al., 2013; Vu et al., 2016). The device structure was further optimized by using $\mathrm{sMoO}_{\mathrm{x}}$ as HIL to expect an even better device performance. Three kinds of QLEDs were fabricated with structures of $\mathrm{ITO} / \mathrm{NiO}_{\mathrm{x}} / \mathrm{QDs} / \mathrm{ZnO} \quad \mathrm{ITO} / \mathrm{Al}, \quad \mathrm{ITO} / \mathrm{sMoO}_{\mathrm{x}} / \mathrm{NiO}_{\mathrm{x}} / \mathrm{QDs} / \mathrm{ZnO}$, and $\mathrm{ITO} / \mathrm{sMoO}_{\mathrm{x}} / \mathrm{NiO}_{\mathrm{x}} / \mathrm{Al}_{2} \mathrm{O}_{3}$ (two cycles)/QDs/ZnO/Al for device I, device II, and device III, respectively. The related optoelectronic characteristic curves were shown in Figure 5, and the corresponding performance parameters were summarized in Table 2. Remarkably, device II with $\mathrm{sMoO}_{\mathrm{x}}$ layer showed a maximum current efficiency of $15.9 \mathrm{~cd} \mathrm{~A}^{-1}$ and an $\mathrm{EQE}$ of $4.3 \%$, which was more than two times higher of that of device I $(7.5 \mathrm{~cd}$ $\left.\mathrm{A}^{-} 1 / 1.7 \%\right)$, and this suggested that the $\mathrm{sMoO}_{\mathrm{x}}$ was comparable to the ultrathin $\mathrm{Al}_{2} \mathrm{O}_{3}$ in improving the efficiency of $\mathrm{NiO}_{\mathrm{x}}$-based QLEDs. The device performance improvement for device II can be ascribed to the $\mathrm{sMoO}_{\mathrm{x}}$ modified layer, which reduced the leakage current and led to a more balanced carrier injection in emitting layer. For device III possessing $\mathrm{sMoO}_{\mathrm{x}}$ layer as well as two cycles of $\mathrm{Al}_{2} \mathrm{O}_{3}$ layer, the maximum luminance was further improved to $9,140 \mathrm{~cd} \mathrm{~m}^{-2}$ at $9.7 \mathrm{~V}$, which was about 1.8 times of that of device II $\left(4,930 \mathrm{~cd} \mathrm{~m}^{-2}\right.$ at $\left.8.5 \mathrm{~V}\right)$. The maximum current efficiency and EQE for device III were $20.4 \mathrm{~cd} \mathrm{~A}^{-1}$ and 5.5\%, respectively, which were about 1.2 times of that of device II. The relatively higher increase in luminance reconfirmed the importance of the $\mathrm{Al}_{2} \mathrm{O}_{3}$ layer in maintaining the high emitting efficiency of the QD layer. The maximum efficiency for device III was obtained at higher-voltage regime, which meant that charge transport became more balanced at higher driving voltage 

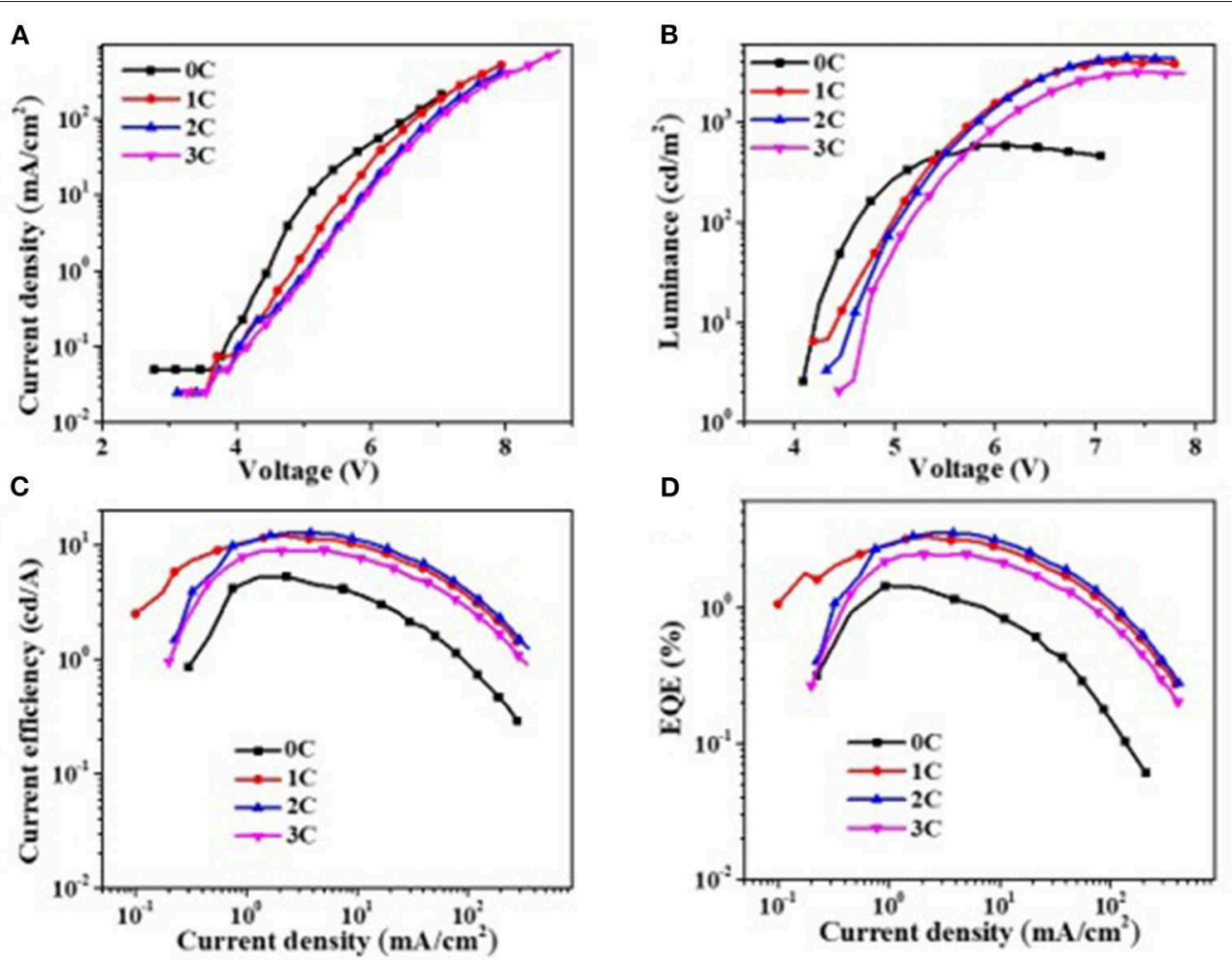

FIGURE 3 | Photoelectric properties of quantum dot light-emitting diodes (QLEDs). (A) Voltage vs. current density (V-J), (B) voltage vs. luminance (V-L), (C) current density-luminous efficiency, and (D) current density-external quantum efficiency. $0 \mathrm{C}$ means 0 cycle deposition of aluminum oxide $\left(\mathrm{Al}_{2} \mathrm{O}_{3}\right)$, each cycle is about $0.1 \mathrm{~nm}$.
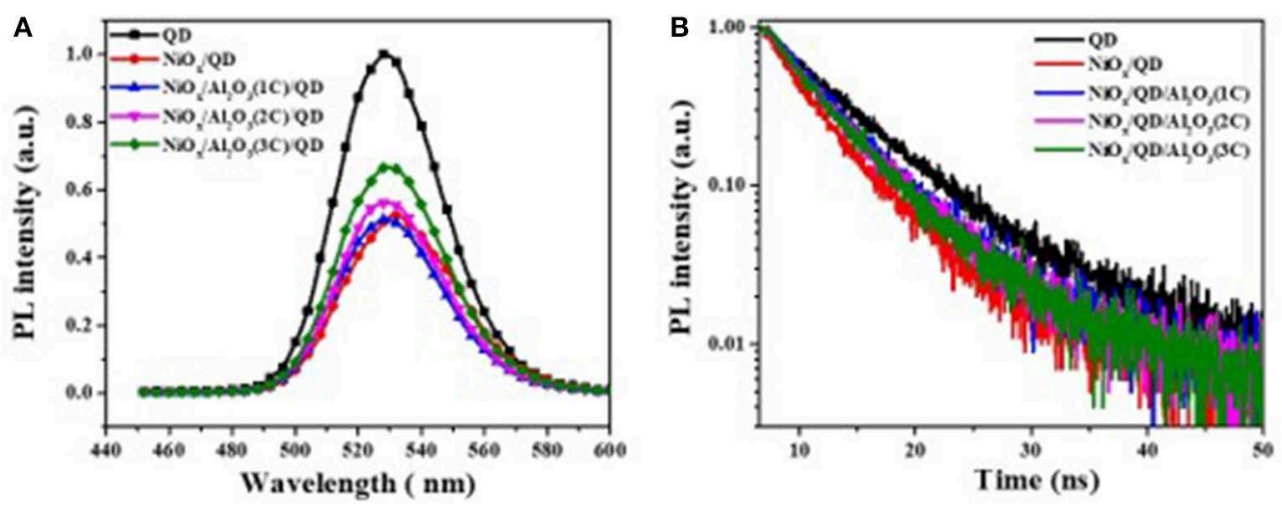

FIGURE 4 | (A) Steady-state and (B) time-resolved photoluminescence (PL) spectra of samples with and without the aluminum oxide $\left(\mathrm{Al}_{2} \mathrm{O}_{3}\right)$ layer.

TABLE 2 | SUmmary of the electrical properties of the QLEDs.

\begin{tabular}{|c|c|c|c|c|c|c|}
\hline Device & $\lambda_{\max }(\mathrm{nm})$ & $\mathbf{V}_{\mathrm{T}}(\mathbf{V})$ & $L_{\max }\left(c d / m^{2}\right)$ & $\mathrm{EQE}_{\max }(\%)$ & $\eta_{\text {Amax }}(\mathrm{cd} / \mathrm{A})$ & $\eta_{\mathrm{P} \max }(\mathrm{Im} / \mathrm{W})$ \\
\hline I & 532 & 3.9 & 3,786 (7.6V) & $1.7(5.3 \mathrm{~V})$ & $7.5(5.3 \mathrm{~V})$ & 4.5 (5.3V) \\
\hline ॥ & 534 & 4.3 & 4,930 (8.5V) & $4.3(5.2 \mathrm{~V})$ & $15.9(5.2 \mathrm{~V})$ & $9.6(5.2 \mathrm{~V})$ \\
\hline
\end{tabular}

EQE, external quantum efficiency; QLED, quantum dot light-emitting diode. 

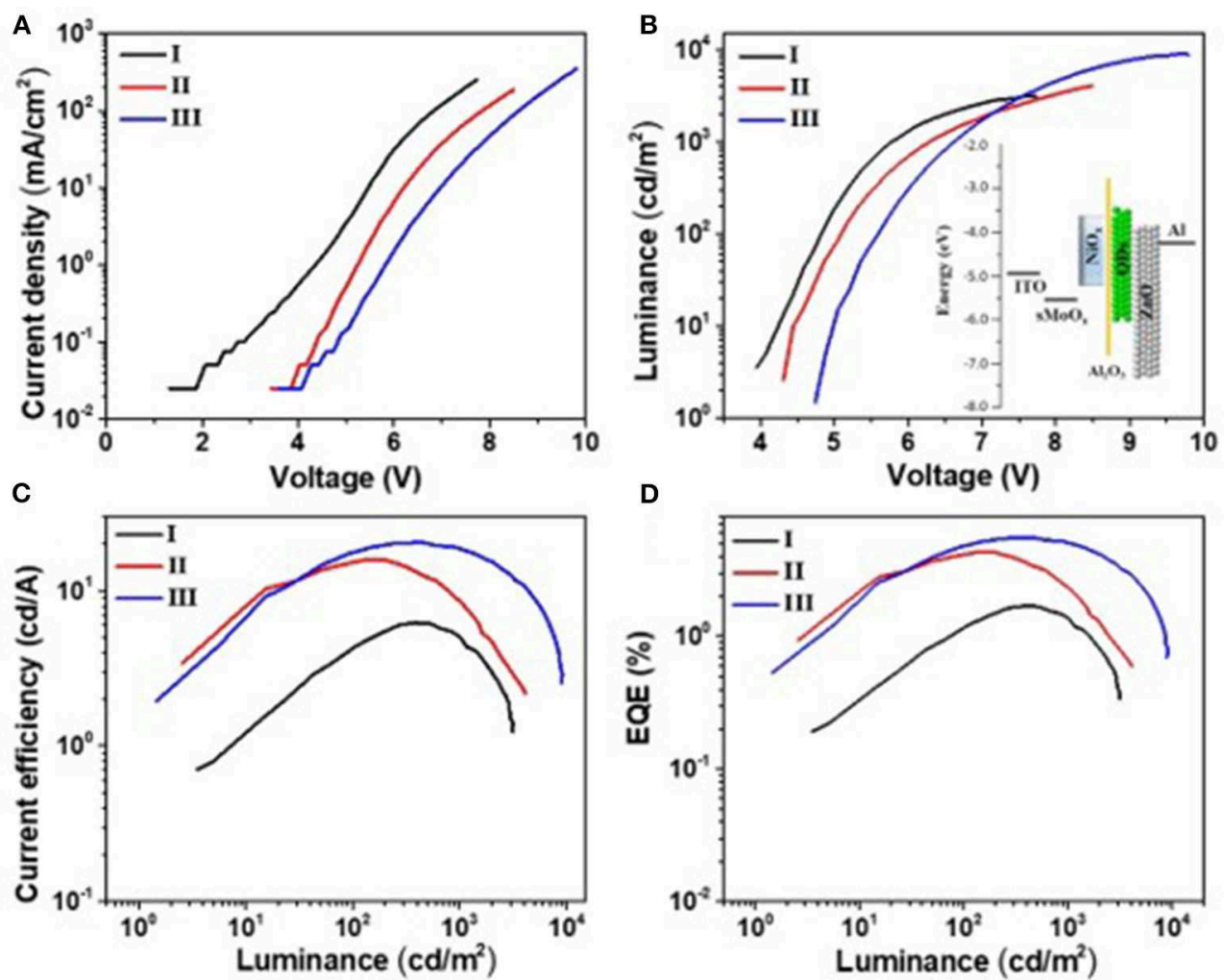

FIGURE 5 | Photoelectric properties of devices I, II, and III. (A) Voltage vs. current density (V-J), (B) voltage vs. luminance (V-L), (C) luminance-Current efficiency, and (D) luminance-external quantum efficiency. The inset in (B) is the energy level diagrams of quantum dot light-emitting diode (QLED) III.
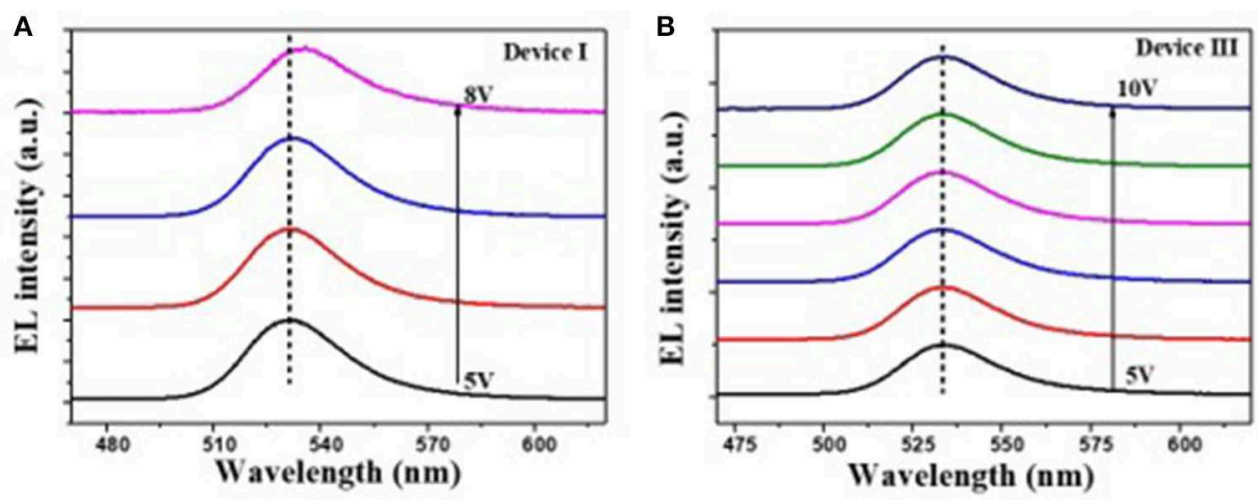

FIGURE 6 | Electroluminescence (EL) spectra of devices I (A) and III (B) under different voltages.

and better tolerance to higher operating voltage for device III than the other two. It is also confirmed from the EL spectra under increasing driving voltage of devices I and III (Figure 6). The EL peak for device I without $\mathrm{Al}_{2} \mathrm{O}_{3}$ layer exhibited a red shift of $4 \mathrm{~nm}$ as the voltage increased to $8 \mathrm{~V}$, while that for device III kept its profile from 5 to $10 \mathrm{~V}$. Despite the slightly higher turn-on voltage, the insertion of $\mathrm{sMoO}_{\mathrm{x}}$ layer combining $\mathrm{Al}_{2} \mathrm{O}_{3}$ layer in $\mathrm{NiO}_{\mathrm{x}}$-based all-organic QLEDs improved not only the device efficiency but also the performance stability.
A comparison of the performance of all-inorganic QLEDs between our work and others in literature was summarized (see Supplementary Table 2).

\section{CONCLUSION}

All-inorganic QLEDs with high efficiency were fabricated using solution-processed $\mathrm{NiO}_{\mathrm{x}}$ as the HTL and $\mathrm{ZnO}$ as the ETL, and ultrathin $\mathrm{Al}_{2} \mathrm{O}_{3}$ was deposited at the $\mathrm{NiO}_{\mathrm{x}} / \mathrm{QDs}$ interface by the 
ALD process to reduce the strong quenching effect of $\mathrm{NiO}_{\mathrm{x}}$ on the QD emission. The corresponding all-inorganic QLEDs exhibited a maximum current efficiency of $19.8 \mathrm{~cd} \mathrm{~A}^{-1}$ and EQE of $4.5 \%$, which is $260 \%$ enhancement compared with the QLEDs without $\mathrm{Al}_{2} \mathrm{O}_{3}$ insertion, making them among the highest efficient inorganic QLEDs. This result suggests that the $\mathrm{Al}_{2} \mathrm{O}_{3}$ passivating layer is critical to device efficiency improvement by suppressing QDs emission quenching induced by $\mathrm{NiO}_{\mathrm{x}}$. Despite great device improvement, the maximum $\mathrm{EQE}$ for $\mathrm{NiO}_{\mathrm{x}}$ all-inorganic QLEDs is still below $10 \%$, which is probably due to the relatively lower hole mobility of $\mathrm{NiO}_{\mathrm{x}}$ and higher energy barrier for hole transfer from $\mathrm{NiO}_{\mathrm{x}}$ to the QD layer, resulting in an imbalanced charge injection in devices. The energy level regulating as well as improving electrical performance of $\mathrm{NiO}_{\mathrm{x}}$ are vital strategies to fabricate high-performance all-inorganic QLEDs.

\section{DATA AVAILABILITY STATEMENT}

All datasets generated for this study are included in the article/Supplementary Material.

\section{REFERENCES}

Anikeeva, P. O., Halpert, J. E., Bawendi, M. G., and Bulovic, V. (2009). Quantum dot light-emitting devices with electroluminescence tunable over the entire visible spectrum. Nano Lett. 9, 2532-2536. doi: 10.1021/nl9002969

Bae, W. K., Brovelli, S., and Klimov, V. I. (2013). Spectroscopic insights into the performance of quantum dot light-emitting diodes. Mrs Bull. 38, 721-730. doi: $10.1557 / \mathrm{mrs} .2013 .182$

Cao, M., Xu, Y., Li, P., Zhong, Q., Yang, D., and Zhang, Q. (2019). Recent advances and perspectives on light emitting diodes fabricated from halide metal perovskite nanocrystals. J. Mater. Chem. C 7, 14412-14440. doi: 10.1039/C9TC03978C

Caruge, J.-M., Halpert, J. E., Bulovic, V., and Bawendi, M. G. (2006). NiO as an inorganic hole-transporting layer in quantum-dot light-emitting devices. Nano Lett. 6, 2991-2994. doi: 10.1021/nl0623208

Caruge, J. M., Halpert, J. E., Wood, V., Bulovic, V., and Bawendi, M. G. (2008). Colloidal quantum-dot light-emitting diodes with metal-oxide charge transport layers. Nat. Photonics 2, 247-250. doi: 10.1038/nphoton.2008.34

Chen, F., Guan, Z., and Tang, A. (2018). Nanostructure and device architecture engineering for high-performance quantum-dot light-emitting diodes. J. Mater. Chem. C 6, 10958-10981. doi: 10.1039/C8TC04028A

Dai, X., Zhang, Z., Jin, Y., Niu, Y., Cao, H., Liang, X., et al. (2014). Solutionprocessed, high-performance light-emitting diodes based on quantum dots. Nature 515, 96-99. doi: 10.1038/nature13829

Han, S. Y., Lee, D. H., Chang, Y. J., Ryu, S. O., Lee, T. J., and Chang, C. H. (2006). The growth mechanism of nickel oxide thin films by roomtemperature chemical bath deposition. J. Electrochem. S 153, C382-C386. doi: $10.1149 / 1.2186767$

He, S., Li, S., Wang, F., Wang, A. Y., Lin, J., Tan, Z., et al. (2013). Efficient quantum dot light-emitting diodes with solution-processable $\mathrm{MoO}$ as the anode buffer layer. Nanotechnology 24:175201. doi: 10.1088/0957-4484/24/17/175201

Huu Tuan, N., Jeong, H., Park, J.-Y., Ahn, Y. H., and Lee, S. (2014). Charge transport in light emitting devices based on colloidal quantum dots and a solution-processed nickel oxide layer. ACS Appl. Mater. Interfaces 6, 7286-7291. doi: $10.1021 / \mathrm{am} 500593 \mathrm{a}$

Ji, W., Liu, S., Zhang, H., Wang, R., Xie, W., and Zhang, H. (2017). Ultrasonic spray processed, highly efficient all-inorganic quantum-dot lightemitting diodes. ACS Photonics 4, 1271-1278. doi: 10.1021/acsphotonics. $7 \mathrm{~b} 00216$

Ji, W., Shen, H., Zhang, H., Kang, Z., and Zhang, H. (2018). Over $800 \%$ efficiency enhancement of all-inorganic quantum-dot light emitting diodes

\section{AUTHOR CONTRIBUTIONS}

All authors listed have made a substantial, direct and intellectual contribution to the work, and approved it for publication.

\section{FUNDING}

The authors gratefully acknowledge the financial support from the National Natural Science Foundation of China (Grant Nos. 51802079, 61922028, 61874039, and 21671058), the Key Project of National Natural Science Foundation of China (Grant No. U1604261), and the Innovation Research Team of Science and Technology in Henan Province (20IRTSTHN020).

\section{SUPPLEMENTARY MATERIAL}

The Supplementary Material for this article can be found online at: https://www.frontiersin.org/articles/10.3389/fchem. 2020.00265/full\#supplementary-material

with an ultrathin alumina passivating layer. Nanoscale 10, 11103-11109. doi: 10.1039/c8nr01460d

Jiang, Y., Jiang, L., Yeung, F. S. Y., Xu, P., Chen, S., Kwok, H.-S., et al. (2019). Allinorganic quantum-dot light-emitting diodes with reduced exciton quenching by a MgO decorated inorganic hole transport layer. ACS Appl. Mater. Interfaces 11, 11119-11124. doi: 10.1021/acsami.9b01742

Li, X., Lin, Q., Song, J., Shen, H., Zhang, H., Li, L. S., et al. (2019). Quantum-dot light-emitting diodes for outdoor displays with high stability at high brightness. Adv. Opt. Mater. 8:1901145. doi: 10.1002/adom.2019 01145

Liu, S., Ho, S., Chen, Y., and So, F. (2015). Passivation of metal oxide surfaces for high-performance organic and hybrid optoelectronic devices. Chem. Mater. 27, 2532-2539. doi: 10.1021/acs.chemmater.5b00129

Manders, J. R., Tsang, S.-W., Hartel, M. J., Lai, T.-H., Chen, S., Amb, C. M., et al. (2013). Solution-processed nickel oxide hole transport layers in high efficiency polymer photovoltaic cells. Adv. Funct. Mater. 23, 2993-3001. doi: 10.1002/adfm.201202269

Mashford, B. S., Nguyen, T.-L., Wilson, G. J., and Mulvaney, P. (2010). All-inorganic quantum-dot light-emitting devices formed via low-cost, wet-chemical processing. J. Mater. Chem. 20, 167-172. doi: 10.1039/B90 $5256 \mathrm{~A}$

Murase, S., and Yang, Y. (2012). Solution processed MoO3 interfacial layer for organic photovoltaics prepared by a facile synthesis method. Adv. Mater. 24, 2459-2462. doi: 10.1002/adma.201104771

Qian, L., Zheng, Y., Xue, J., and Holloway, P. H. (2011). Stable and efficient quantum-dot light-emitting diodes based on solution-processed multilayer structures. Nat. Photonics 5, 543-548. doi: 10.1038/nphoton. 2011.171

Ratcliff, E. L., Meyer, J., Steirer, K. X., Garcia, A., Berry, J. J., Ginley, D. S., et al. (2011). Evidence for near-surface $\mathrm{NiOOH}$ species in solution-processed $\mathrm{NiOx}$ selective interlayer materials: impact on energetics and the performance of polymer bulk heterojunction photovoltaics. Chem. Mater. 23, 4988-5000. doi: $10.1021 / \mathrm{cm} 202296 \mathrm{p}$

Sasi, B., and Gopchandran, K. G. (2007). Nanostructured mesoporous nickel oxide thin films. Nanotechnology 18:115613. doi: 10.1088/0957-4484/18/11/115613

Shen, H., Cao, W., Shewmon, N. T., Yang, C., Li, L. S., and Xue, J. (2015). Highefficiency, low turn-on voltage blue-violet quantum-dot-based light-emitting diodes. Nano Lett. 15, 1211-1216. doi: 10.1021/nl504328f

Shen, H., Gao, Q., Zhang, Y., Lin, Y., Lin, Q., Li, Z., et al. (2019). Visible quantum dot light-emitting diodes with simultaneous high brightness and efficiency. Nat. Photonics 13, 192-197. doi: 10.1038/s41566-019-0364-Z 
Shirasaki, Y., Supran, G. J., Bawendi, M. G., and Bulovic, V. (2013). Emergence of colloidal quantum-dot light-emitting technologies. Nat. Photonics 7, 13-23. doi: $10.1038 /$ nphoton. 2012.328

Song, J., Wang, O., Shen, H., Lin, Q., Li, Z., Wang, L., et al. (2019). Over 30\% external quantum efficiency light-emitting diodes by engineering quantum dot-assisted energy level match for hole transport layer. Adv. Funct. Mater. 29:1808377. doi: 10.1002/adfm.201808377

Vu, H.-T., Su, Y.-K., Chiang, R.-K., Huang, C.-Y., Chen, C.-J., and Yu, H.C. (2016). Solution-processable MoOx for efficient light-emitting diodes based on giant quantum dots. IEEE Photon. Technol. Lett. 28, 2156-2159. doi: 10.1109/LPT.2016.2578643

Wang, L., Lin, J., Hu, Y., Guo, X., Lv, Y., Tang, Z., et al. (2017). Blue quantum dot light-emitting diodes with high electroluminescent efficiency. ACS Appl. Mater. Interfaces 9, 38755-38760. doi: 10.1021/acsami.7b10785

Wu, X., and Yeow, E. K. L. (2010). Charge-transfer processes in single CdSe/ZnS quantum dots with p-type $\mathrm{NiO}$ nanoparticles. Chem. Commun. 46, 4390-4392. doi: $10.1039 / \mathrm{c} 0 \mathrm{cc} 00271 \mathrm{~b}$

Yang, X., Ma, Y., Mutlugun, E., Zhao, Y., Leck, K. S., Tan, S. T., et al. (2014). WO3, TPD. ACS Appl. Mater. Interfaces 6, 495-499. doi: 10.1021/am404540z

Yang, X., Zhang, Z.-H., Ding, T., Wang, N., Chen, G., Dang, C., et al. (2018). Highefficiency all-inorganic full-colour quantum dot light-emitting diodes. Nano Energy 46, 229-233. doi: 10.1016/j.nanoen.2018.02.002
Zhang, H., Hu, N., Zeng, Z. P., Lin, Q., l., Zhang, F., Tang, A., et al. (2019). Highefficiency green InP quantum dot-based electroluminescent device comprising thick-shell quantum dots. Adv. Opt. Mater. 7:9. doi: 10.1002/adom.201801602

Zhang, H., Sui, N., Chi, X., Wang, Y., Liu, Q., Zhang, H., et al. (2016). Ultrastable quantum-dot light-emitting diodes by suppression of leakage current and exciton quenching processes. ACS Appl. Mater. Interfaces 8, 31385-31391. doi: 10.1021/acsami.6b09246

Zhang, H., Wang, S., Sun, X., and Chen, S. (2017). Solution-processed vanadium oxide as an efficient hole injection layer for quantum-dot light-emitting diodes. J. Mater. Chem. C 5, 817-823. doi: 10.1039/C6TC04050K

Conflict of Interest: The authors declare that the research was conducted in the absence of any commercial or financial relationships that could be construed as a potential conflict of interest.

Copyright (C) $2020 \mathrm{Xu}, \mathrm{Li}$, Lin, Shen, Wang and Du. This is an open-access article distributed under the terms of the Creative Commons Attribution License (CC BY). The use, distribution or reproduction in other forums is permitted, provided the original author(s) and the copyright owner(s) are credited and that the original publication in this journal is cited, in accordance with accepted academic practice. No use, distribution or reproduction is permitted which does not comply with these terms. 